\title{
ROLE OF TREES IN MITIGATING URBAN HEAT ISLAND IN CHARLOTTE, NORTH CAROLINA, USA
}

\author{
VERONICA E. WESTENDORFF \\ Infrastructure and Environmental Studies, The University of North Carolina at Charlotte, USA
}

\begin{abstract}
Urban Heat Island (UHI) is a complex phenomenon experienced by cities around the globe, resulting in increased heat retained by dark, often impervious surfaces which gain and hold heat during the day and slowly release heat over the nighttime. The result is higher nighttime surface temperatures which start the city at higher temperatures the following morning. These increased night-time temperatures affect plant growth, agriculture, habitat, animal life and even human health and well-being. As daily temperatures rise worldwide, this effect has been increasing, although the factors which can impact the intensity of UHI are not well understood. Managing UHI plays an important role in the future success of sustainable cities. Trees provide moderation of UHI as well as many other benefits to human health and climate change management and, as a result, can be part of the plans for policy development that will influence the future design of our cities. Urban green spaces can help reduce the UHI effect and impact social equity by reducing energy costs, improving human living conditions, providing food and habitat to wildlife and improving aesthetics and land values.
\end{abstract}

Keywords: Urban Heat Island, Green Infrastructure, ecosystem services, sustainability, urban planning, policy, urban green spaces, social costs, social benefits, social equity,

\section{INTRODUCTION}

Cities are the largest consumers of ecosystem services, relying on land for housing, business, transportation, waste disposal and providing resources for energy, water and food. While cities offer many opportunities for a better life, their current growth patterns are not sustainable and are adding to the climate crisis across the globe. Valuable resources and ecosystem services are being lost and the implication for human health and wellbeing is more apparent as time passes. This paper will explore the role that "greening" of urban spaces plays in the creation of sustainable and improved cities through a review of literature and analysis of the connection between land cover, and Urban Heat Island effect. The introduction of green spaces in urban areas through green infrastructure, streetscapes, green roof and walls, street trees, urban forests and restored ecosystem services will improve the sustainability of cities and provide benefits to both humans and ecosystems. Changes to the green fabric of a city provide benefits and this study may offer planners the tools to support policy changes and prioritization of works to increase the sustainability of cities.

Urban environments are experiencing higher temperatures due to increased infrastructure, development, impervious area, deforestation and climate change. Urban areas range from $1.8-5.4^{\circ} \mathrm{F}$ above those of surrounding rural areas in the daytime, to $22^{\circ} \mathrm{F}$ higher at night (Benefits of Trees [1]). UHI occurs in urban areas due to the high area of impervious areas especially dark surfaces that hold heat, and can disrupt the health, well-being and effective functioning of a city (US EPA [2]) with long term consequences to climate change, health and sustainability of cities. Energy usage increases within these urban areas by $1.5-2 \%$ per ${ }^{\circ} \mathrm{F}$ increase above $68-77^{\circ} \mathrm{F}$ for cooling [2]. This has a huge effect on social costs beyond the rising cost and stressors on the electric grid. These costs include threats to human health from increasing temperatures, lung disease from increased pollutants, and increased insect populations including mosquitoes that carry diseases that impact human populations (National Climate Assessment [3]). 


\section{OBJECTIVE}

The objective of this project is to explore the role trees play in improving the UHI effect and the sustainability of cities and recommend supporting policies directed by municipalities for green space and for street tree plantings and planting areas to reduce UHI and ensure better survival of plant species. Planning departments for municipalities hold a key role in managing the urban environment to reduce the impacts of climate change. Urban green space, particularly trees, bring benefits to the urban environment, such as shade and moisture which combined can create microclimates that reduce the heat effects of urban areas (ASLA [4]). New development creates environments that are often hostile to supporting plant material. Green spaces are one of the last pieces of projects to be installed, and face cut budgets that create less than ideal conditions for successful results. Looking at the relationship between UHI and land cover types including street trees and urban green space, would help support the implementation of policies to mitigate UHI and improve climate regulation in urban areas.

This paper also seeks to use free, open source data to research these concepts to create a method of determining Land Use/Land Cover benefits to be accessible to any city, regardless of budget or size to assist in determining the best land covers, best ecosystem services, appropriate mitigation options and greatest benefits to the citizens. This is especially important because each city has a unique UHI characteristic (Eastin et al. [5]) and needs to evaluate their location independently from other cities in order to evaluate policies for funding and placement of green spaces. A one size all approach is not effective for managing ecosystem services like UHI reduction, and a solution that is accessible to all is vital.

\section{METHODOLOGY}

Green spaces in the context of urban settings provide multiple services from ecosystem services like air quality, water quality, habitat, erosion control, food provisioning (TEEB [6]) to mental health, physical health, wellbeing, aesthetics and cultural and spiritual benefits (Langemeyer et al. [7]). Urban Heat Island is one of the main climate issues faced by urban areas (Marando et al. [8]). To understand the impact of green spaces on reducing UHI in cities, a literature review, followed by a specific methodology to analyze the correlation of land cover and UHI was used with Charlotte, NC as the case study for this research.

\subsection{Literature review/current state of knowledge}

UHI is characterized by a rise in temperatures of urban areas due to greenhouse gas emissions, increased numbers and sizes of buildings, transportation, and heat adsorption by these surfaces (Gomez-Baggethun and Barton [9]). These changes in urbanization create urban climates which absorb and hold heat from daylight hours and release this heat slowly over the night, resulting in higher nighttime temperatures in the cities versus rural or even suburban areas (Norton et al. [10]). Larger and more populous cities are feeling the effects of UHI and now there is more research available to document how these changes affect not only humans and animals [8] but also building efficiency and equipment longevity and functioning (Miner et al. [11]).

William Hertel [12] published a review of UHI for 64 cities across the globe. This method of identifying variables that influence urban heat island offers an understanding of the effects each variable has on UHI in cities with differing characteristics. The use of multiple cites allows a broad exploration of climate and geographical features that increases the understanding of which variables have the greatest impact on UHI. This analysis also informs best choices for mitigation strategies that work for conditions specific to individual cities. These data come from the Integrated Surface Global Hourly data set (ISH) retrieved from the 
National Climatic Data Center (NCDC), which has either hourly or 3 hour spaced data on climatic conditions including temperatures, dew point, wind speed and direction, pressure and sky cover.

Washington, D.C. has several interesting programs and ordinances directed at reducing UHI. Sustainablity D.C. documents the plans that DC has developed starting in 2011 to improve sustainability through community involvement, targets, goals and implementation strategies (Sustainability D.C. [13]). Changes to parking requirements reduce paved areas through zoning changes and move to requiring underground parking. Washington, D.C. also that requires all new construction to adhere to green building codes. A connectivity map will help guide development to ensure green corridors and areas of connected habitat have trees and green spaces all new developments.

Stuttgart, Germany, is a model for "cool city" principles which are directly related to reducing UHI effects (Rehan [14]). These include reducing the volume of global emissions, creating smart growth and cool community scenarios. Stuttgart's policies support the implementation of green infrastructure and green spaces, using trees and vegetation to shade buildings, decreasing demand for cooling $\mathrm{AC}$, maintaining pavements through tree canopy shading and promoting cooling in urban environments.

The European Union encourages the use of Green Infrastructure (GI) as a nature-based solution to managing and mitigating UHI in urban areas [8]. GI includes using plants including trees, shrubs, ground covers, bioswales, urban forests, green roofs and green walls to manage storm water, reduce flooding, create cool areas, reduce energy demand and enhance human well-being (Jennings et al. [15]). These natural connective networks of green spaces provide many ecosystem services (ES) that reduce pollution and reduce UHI impacts on human health [8]. Trees and urban forests overall reduce temperatures in cities by blocking solar radiation, adsorbing this radiation, and through evapotranspiration from the leaves which lowers the overall canopy temperature as well as the surrounding area surface temperatures. Marando's study of Rome, Italy showed a difference in land surface temperatures in both summer and winters seasons, with average differences between urban and rural areas ranging from 1 to $4^{\circ} \mathrm{C}$, with a strong correlation between surface type and temperature. Land Surface Temperatures (LST) in Rome were shown to be highly influenced by the presence of vegetation, especially in the hot summers [8].

Open green space (not lawn), tree canopy, green roofs and vertical greening screens all provide some benefit to reducing UHI, but overhead vegetation, mainly tree canopies provides one of the best options for mitigations of UHI (Norton et al. [10]). Marando et al. [8] found canopy cover in green spaces increased their ability to regulate urban climates and reduce UHI and Elmqvist et al. [16] found that a $10 \%$ increase in tree cover can create a reduction of $3-4^{\circ} \mathrm{C}$ in ambient air temperatures. This decrease in temperature then reduced the energy usage from air conditioning, which further reduced consumption of fossil fuels to create the energy needed for cooling, creating a chain effect of reduction that improves air quality in cities and reduces UHI. Trees are able to sequester carbon which helps regulate climate [9]. Decreasing UHI also decreases the number of heat related illnesses and mortality (Escabedo [17]).

Understanding the plant physiology and morphology i.e. "horticultural limitations" is extremely important in ensuring the desired results from the investment in green spaces and urban trees [10]. For the benefits to be received, the plants must survive. Efforts and precautions to increase the health and longevity of the trees and other plants used in the green spaces are needed in order to reap the benefits to UHI mitigation. Typical life expectancy of an urban street tree is less than 10 years [16] and the true benefits of trees in UHI reduction come with the growth and maturity of the tree. Time is an essential factor in determining and 
using street trees to reduce UHI and improve the city's health, especially in vulnerable areas that lack the funding for replacement plants. If vegetation and GI are to work successfully, they must be installed and maintained properly to achieve long term growth and benefits. Not all vegetation is equal however; some trees and plants release biogenic hydrocarbons and not all have the high leaf area index with the greatest capacity to remove air quality contaminants [15]. There are also a number of other disservices which should be considered when evaluating the benefits of specific green spaces to reduce UHI in cities. These include damage to buildings and infrastructure from roots, limbs falling or storm damage, allergies and asthma from pollen and leaf litter, view and sign blockages, safety and fear issues from overgrown vegetation, and habitat competition from insects, rats, squirrels and pests [9]. These disservices are often neglected in planning and cost analysis of urban green spaces [17] and should be included when looking at policies and cost benefit analysis of green spaces.

In Barcelona, Spain researchers looked at cultural value as an ecosystem service of greenspaces [7]. Land use maps and management data bases, planning documents and local experts were used to classify the green spaces as cultural facilities, parks and gardens, semi-natural or sport facility. Norton et al. [10] collected satellite or airborne sensed data, visual surveys, LiDAR, and GIS data to determine land cover types and compare these to temperature data. This was used to identify urban areas that were referred to as "hot spots" and then to prioritize those areas for the use of GI to mitigate UHI. Open space (non-lawn), shade trees, green roofs, vertical greening were all evaluated, with overhead vegetation and canopy cover from street trees one of the most beneficial at reducing UHI.

UHI has many complicated influences that include meteorological conditions, the form of the urban spaces, and human action. Biomes, wind conditions, cloud cover, pollution levels, humidity, location of water bodies, season of the year, location, topography, and existing policies are unique to each city and impact UHI [5]. In Rome, Marando et al. [8] used remotely sensed Land Surface Temperatures (LST) from LANDSAT-8 OLI/TIRS images for summer and winter day and nighttime temperatures for 2013-2017. Hertel [12] employed data from the Integrated Surface Global Hourly data set (ISH) retrieved from the National Climatic Data Center (NCDC) including temperatures, dew point, wind speed and direction, pressure and sky cover. Spatial satellite imagery was used to analyze the urban forms of different cities, looking at patch shape, fragmentation, and proportion of open space. These data can be used to expand our understanding of urban ecology to include human health benefits and social justice concerns. Higher levels of biological diversity in an ecosystem have been linked to greater restoration value from green spaces. And this diversity of species is less apparent in disadvantaged communities [10].

\subsection{Case study Charlotte, NC}

Charlotte, NC, located at longitude -80.9491, latitude 35.2137, is the largest city in North Carolina with a population of 808,830 in the city and 1,011,770 in Mecklenburg County as of September 2018 (The Demographic Statistical Atlas of the United States, [18]). Annual average high temperatures are $71^{\circ} \mathrm{F}$ and low temperatures are $49^{\circ} \mathrm{F}$, with 41.63 " of average annual precipitation and 4" average annual snow fall. Over the last 30 years, the number of days with temperatures over $95^{\circ} \mathrm{F}$ has increased dramatically (see Fig. 1), and this trend is expected to continue [3].

For future work, the Mecklenburg County POLARIS website and on-site verification will supplement data and images as needed. The data can be used to map the different land cover types across the city over a period of time and compare those to daytime and nighttime 
temperatures across the city. Cells of identical size laid across the map show where most of the green spaces in Charlotte are located and identify areas with little to no coverage. Hot spots of UHI can be determined, and areas that coincide with high UHI temperatures signal a need for prioritization for programs, policy and funding to address the problem. This procedure will identify correlation, and areas of inequity and excessive heat. Initially, discerning the patterns of UHI can be established through a visual inspection of these layered maps to find hot spots of UHI, looking for tree cover, and later, land cover type (impervious, urban forest, green infrastructure, green space, bare earth etc.) under each hot area.

\section{Projected Change in Number of Days Over $95^{\circ} \mathrm{F}$}
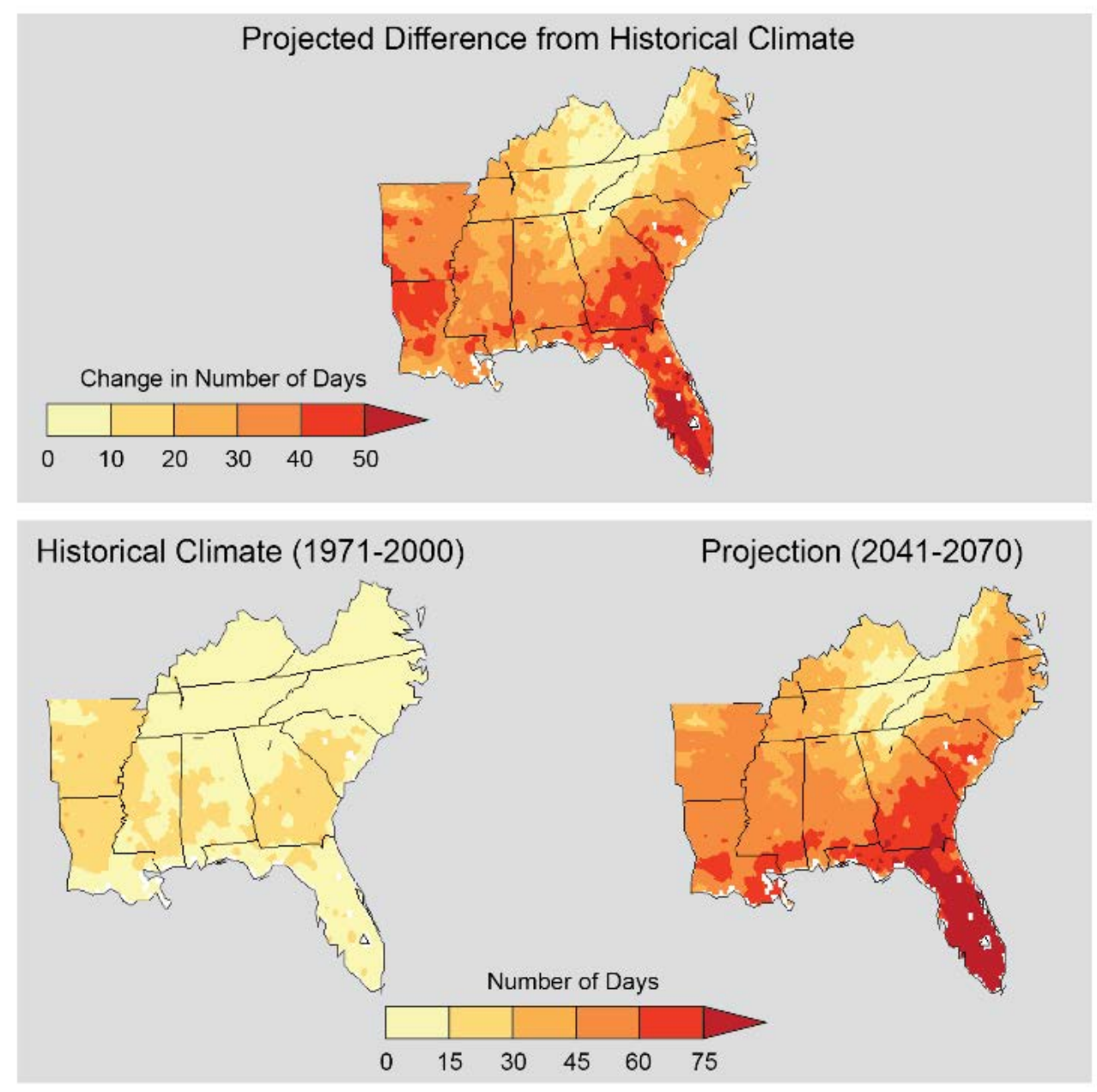

Figure 1: The Third National Climate Assessment report shows Charlotte, NC has an above median increase of 30-45 more days per year over $95^{\circ} \mathrm{F}$. (Source: Melillo et al. [19].) 


\section{ANALYSIS}

As a first step in this study, the base map using ArcGIS and data from the Multi Resolution Land Characteristics (MRLC) was created using the Open Street Mapping data for Mecklenburg County. Tree cover canopy density as a percent of coverage from Global Forest Watch for year 2000 was added, and finally Urban Heat Island relative heat severity for the summers of 2018-2019 was included. Each layer was set to a transparency of 50\% to allow the other layers to be visible (see Figs 2 and 3 below). It is immediately apparent where the interstates 77, 85 and 485 are as well as the Charlotte Douglas International Airport and denser and more urban centers of the county. Impervious areas that absorb and hold heat can be seen in gradients labeled from 1-5 with 1 showing areas slightly above the mean for the city and 5 as a severe heat area significantly above the mean for the city. Impervious areas show up as the highest gradients, but other areas also show increased heat adsorption and retention. In comparison, when tree cover layers are added to the same maps, it emphasizes the impervious areas as having the highest temperatures. Roadways and heavily impervious and built out areas show the most intense temperature increases, but of more interest to this study, is what types of land covers are around areas that are impervious but cooler, and what land covers are in hot areas that are not impervious. For example, sections of I-85 located near wooded areas are cooler than stretches of the interstate that are treeless. New development with small or no street trees appears as hotter, while older areas with larger trees register as cooler.

Currently, the city of Charlotte and towns that make up Mecklenburg County have street tree requirements that support the planting of trees for shade and erosion control. Trees are required to be 3" caliper diameter at breast height (dbh). This allows for a large enough tree at installation without the risk of "shocking" the tree into an early demise. Streets without overhead utilities are planted with large maturing street trees spaced at 1 tree every 40'. Where there are limiting factors such as utilities overhead, small maturing trees are planted with 1 tree every 30' (Code of Ordinance, [20]). Tree save areas are required as part of new plans for approval and trees are required within 60' of every parking space in parking lots of a certain size, and as buffer and perimeter plantings. While these trees do provide the beginnings of a means to mitigate UHI, they do not include single family developments and only require this minimum. When trees provide cover of $40 \%$ or more, the streetscape is cooled more than the UHI created by the absorbed heat from impervious surfaces (Weston, 2019). This suggests that both quantity and canopy spread (age and health) are important factors in reducing the effects of rising urban temperatures. TreesCharlotte [21], a local organization created to help Charlotte reach a tree canopy coverage of $50 \%$ by 2050 , estimates that Charlotte currently has a $47 \%$ canopy cover. Despite this positive number, many of Charlotte's trees are declining in health while continued growth and development are impacting the existing tree canopy. The Charlotte Tree Ordinance planting requirements create a tree canopy in new developments in public areas (streets and parking) of approximately $10 \%$ coverage (Chatham Park [22]). $40 \%$ coverage has been shown to reduce the effect of UHI (Weston [23]), so for Charlotte to impact the coverage by tree planting, the number of trees required in these public spaces will need to increase to 4 times the number required now.

The City of Charlotte currently has programs and policies in place to support the use of trees in the city. The City of Charlotte Code of Ordinances dictates tree preservation, Heritage tree designation, tree save areas as a percentage of developed site area and mitigation options including off site mitigation, restoration and payment in lieu [20]. 


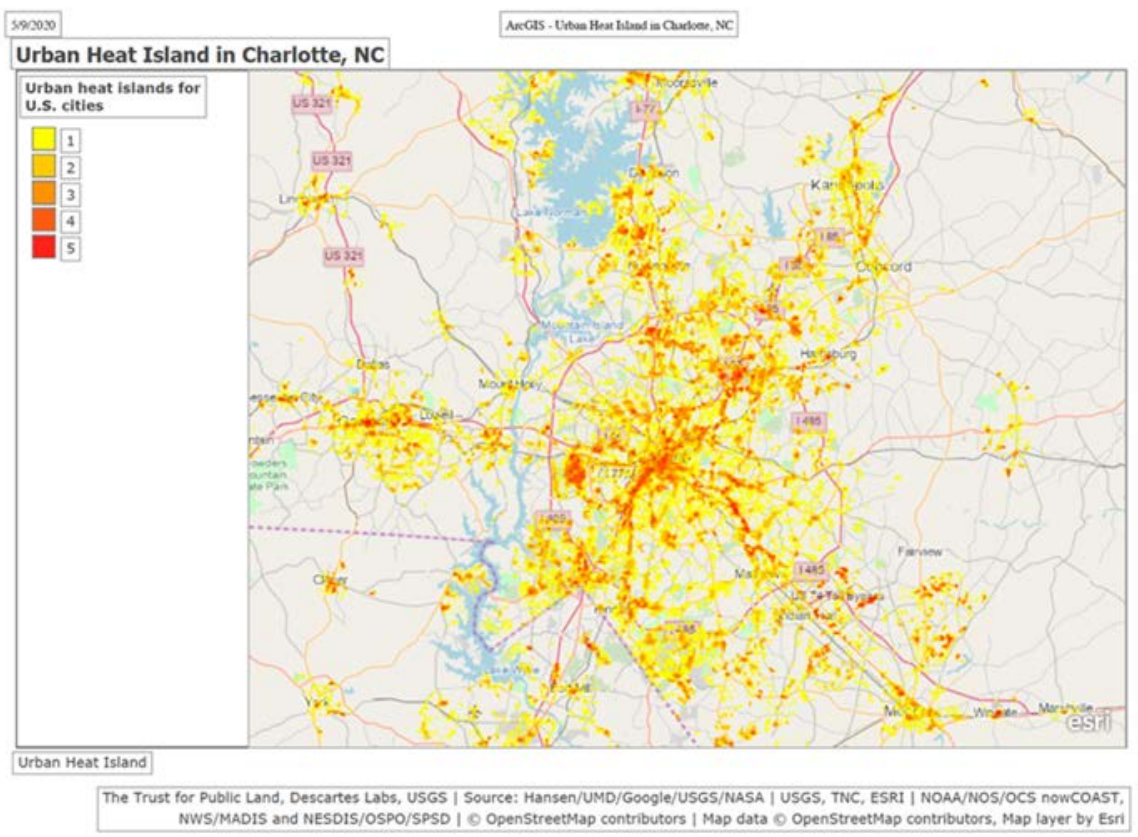

Figure 2: Urban Heat Island in Charlotte.

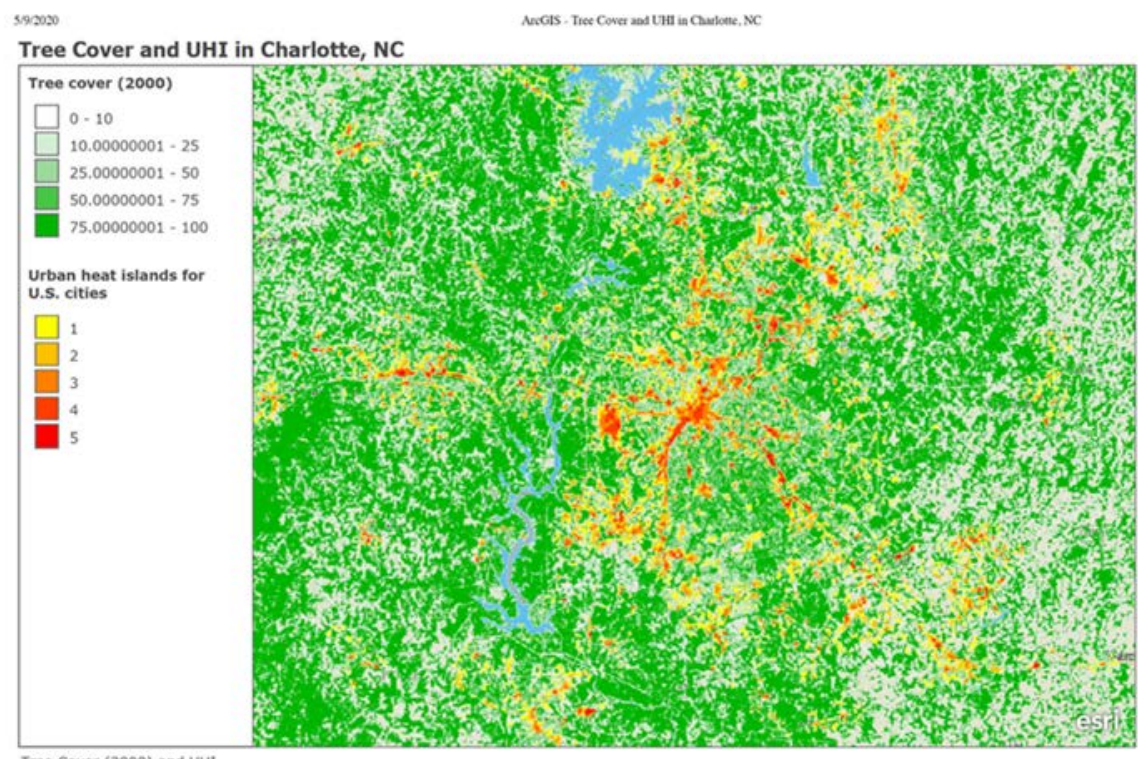

Tree Cover (2000) and UHI

The Trust for Public Land, Descartes Labs, USGS | Source: Hansen/UMD/Google/USGS/NASA | USGS, TNC, ESRI | NOAA/NOS/OCS nOWCOAST, NWS/MADIS and NESDIS/OSPO/SPSD I 0 OpenStreetMap contributors I City of Charlotte, NC, Esri, HERE, Garmin, SafeGraph, FAO, METI/NASA, USGS,

Figure 3: Urban Heat Island and tree cover in Charlotte. 
These policies acknowledge that trees are vital to the health of the city, and that there is a greater value to existing and larger trees that is not easily replaced by new plantings. Trees increase the shade coverage which helps reduce UHI, reduce energy costs, improve the quality of the air, increase evapotranspiration, which in turn cools the air. They also provide additional ecosystem services including habitat, erosion control, water quality, human health and aesthetics. New plantings are required to fulfill streetscape plans, perimeter parking and interior lot and parking plantings through section 21 of the Code of Ordinance. Perimeter screening of parking areas call for a minimum of $75 \%$ evergreen shrubs and require each parking space be within $40^{\prime}$ of a tree, or $60^{\prime}$ if there is a continuous planting strip. Urban zoning requirements adjust planting requirements to meet the needs of the increased impervious area on projects (Code of Ordinances Section 9). These codes still include providing shrubs to screen parking and different uses, in addition to fencing for screening, giving value to the role green plays in improving the city. Street trees and streetscape per approved plans are also required, with the City of Charlotte providing direction on streetscape requirements on a neighborhood and project level.

Erosion Control in the Code of Ordinances (Section 17) provides protection from 10-year storms. Erosion control plans are required of any development greater than 1 acre. The length of time the soil remains disturbed is vital as bare soil during construction has a similar heat effect as impervious areas ( $\mathrm{Li}$ et al. [24]). A post construction ordinance (Code of Ordinances Section 18) is also in place to set requirements for developed sites after the construction is completed, which include maintaining buffers and existing vegetation. Incentives are provided for additional tree save areas and open space in the form of added density for development. In single family residential development, developers are encouraged to reduce yard size through reduced setbacks, density bonus, smaller lot sizes permitted and clear-cutting site prior to construction is discouraged.

The Charlotte Tree Ordinance directs tree plantings for new and existing development through required tree plans. It provides for tree protection and planting directions, updates the approved tree and shrub list, gives urban forestry tree planting and preservation standard notes. The City Arborist oversees the administration of the ordinance, including direction for the maintenance of the trees on private land as well as public right of way. When minimum planting tree save area requirements are not met, supplemental planting is required. Soil amendment requirements, approved tree and shrub list for public planting spaces, requirements of $50 \%$ native trees, minimum width of planting strips, spacing of street trees, tree pits, pavement cutouts on renovated sites, and $75 \%$ of trees as large maturing shade trees are examples of how the Code of Ordinances sets policy for the improvement of UHI. An updated code is in process, the Unified Development Ordinance (UDO) due to be completed by 2021 , that will combine the multiple ordinances and policies, further streamlining the policies and programs in use in the City of Charlotte. This addition is part of the Charlotte Future 2040 plan and has a strong focus on smart growth and sustainability (DOEE [25]).

Other programs outside of the City of Charlotte include Mecklenburg County's Land Use and Environmental Service Agency (LUESA) and a public/private partnership with Center City Partners which looks at ways to increase sustainability and circular economy in Charlotte. Non-profits like TreesCharlotte offer free trees to residents and planting in neighborhoods and school yards. Envision Charlotte, a public-private collaboration, works to reduce energy consumption, which plays a large role in increasing UHI, by commercial properties located in the urban core of Charlotte. Their programs collect data, define policies, and act as a living laboratory for change within Charlotte. 


\section{IMPLICATIONS}

It is clear that Charlotte has taken the first steps toward improving ecosystem services and reducing the impacts of UHI through the current policies and programs, more effort is needed to adapt to the changing climate and fast paced growth that is impacting the green spaces of the city. Creation of a climate action plan that is integrated with the UDO in the Charlotte Future 2040 plans is necessary. In it, an overarching master plan of the trees, green spaces, green infrastructure, green corridors need to be documented and strategically added to and mapped out. The US Environmental Protection Agency recommends focusing on three policies in particular to create impact to UHI: tree protection, parking lot ordinances, and street tree ordinances [2]. Areas which lack green spaces or are hot spots should be located, clusters identified and neighborhoods lacking access and green spaces should be prioritized. Green spaces would take the form of streetscapes, green infrastructure, green roofs and facades, parks, lawns, and with appropriate planning, would create corridors of cooling air flow, habitat connections and networks of green infrastructure to reduce UHI and enhance ecosystem services. Reducing energy usage will also improve UHI. More shade, whether from trees, green roofs or green facades, reduces the need for air conditioning which generates large amounts of heat [10]. Walking and cycling reduce vehicle usage, which reduces heat and greenhouse gases which trap heat and adding green corridors to these trails not only encourages higher use, it can create cooling corridors throughout the city. Implementation of Green Building strategies such as Energy Star, LEED and SITES AP ensures higher standards of planning, construction, implementation and maintenance.

While advanced planning to allocate larger areas of green space is ideal, changes to even small areas can make a large difference, especially to residents [10]. Areas with high usage, such as bus and transit stops, public gathering spaces, schools and community centers and pedestrian and cycle paths should be prioritized. Wherever possible, trees and green infrastructure should be used, but building placement, screens, canopies, reflective colored surfaces and other forms of shade should be used when plantings are not feasible, sustainable or of a size for immediate relief. Addressing requirements for new development to use better planting techniques and practices, using percentage of tree cover, not tree counts, as a guide, encouraging more tree save areas and mitigation, reducing construction waste and encouraging circular economy ideals are valuable steps for improving UHI.

A review of the literature in the reference section of this paper alone shows the importance of green infrastructure in regulating urban heat island effects, particularly urban trees. Given that there is "growing evidence on the positive impacts of urban ecosystem services on quality of life in cities" [9], and a net gain in the value and benefits of urban street trees, the use of trees to mitigate UHI effects is a valuable resource. To achieve the desired reduction of temperatures caused by UHI effect, an increase from $10 \%$ to $40 \%$ canopy coverage is needed. This translates to 4 times the number of trees required per project. Grouping trees in clusters will increase the canopy coverage while reducing the land use requirements and may save additional costs to future projects.

Beyond reducing UHI, there are many ecosystem services that are improved with the addition of green spaces in cities. Urban forests provide shade but also provisioning services such as food sources, natural resources and habitat; regulating services like cleaning water and air and sequestering carbon; cultural services that include aesthetics, historic landscapes, recreation and sense of place; and supporting services that include nutrient cycles, soil formation and oxygen creation. The quality, type, and placement of green spaces has been shown to have impacts on human health and well-being [15] and therefore offer many benefits to the inhabitants of cities. These include heat mitigation (UHI), aesthetics and connectedness with spirit of place, interaction with nature, storm water management, flood 
control, physical activity and recreation for human health and fitness, improved mental function and cognitive abilities. With that in mind, how these urban spaces are designed alongside their green spaces is an important link to human well-being and the success of cities. As urbanization continues, we will need to "strategically conserve and manage our natural resources" [15].

Future work will expand on this research, including expanding the mapping and documenting of which other green spaces have a mitigating impact. The role of trees in mitigating UHI in Charlotte will be expanded to Census block level, and additional information of other GI and greenspaces will be explored, with references to appropriate changes to current policy.

\section{REFERENCES}

[1] Benefits of Trees, 10 April 2012, http://www.urbanreleaf.org/get-educated/benefitsof-trees. Accessed on: 29 Apr. 2019.

[2] US EPA, Heat Island Impacts. Overviews and Factsheets, 17 June 2014. www.epa.gov/heat-islands/heat-island-impacts. Accessed on: 29 Apr. 2019.

[3] National Climate Assessment, https://nca2014.globalchange.gov/node/1954 Accessed on: 29 Apr. 2019.

[4] ASLA.org, Resilient Design: Extreme Heat. www.asla.org/extremeheat.aspx?utm medium $=$ social\&utm_source=linkedin.company\&utm_campaign=postfity\&utm content=postfity1d316. Accessed on: 29 Apr. 2019.

[5] Eastin, M.D. et al., Temporal variability of the Charlotte (sub)Urban Heat Island. Journal of Applied Meteorology and Climatology, 57(1), pp. 81-102, 2017. https://doi.org/10.1175/JAMC-D-17-0099.1.

[6] The economics of ecosystems and biodiversity (TEEB). http://doc.teebweb.org/wpcontent/uploads/2017/03/TEEB-for-Policy-Makers_Website.pdf.

[7] Langemeyer, J., Baró, F., Roebeling, P. \& Gómez-Baggethun, E., Contrasting values of cultural ecosystem services in urban areas: The case of park Montjuïc in Barcelona. Ecosystem Services, 12, pp. 178-186, 2015. https://doi.org/10.1016/j.ecoser.2014.11.016.

[8] Marando, F. et al., Regulating ecosystem services and green infrastructure: Assessment of Urban Heat Island effect mitigation in the municipality of Rome, Italy. Ecological Modelling, 392, pp. 92-102, 2019. https://doi.org/10.1016/j.ecolmodel.2018.11.011.

[9] Gómez-Baggethun, E. \& Barton, D., Classifying and valuing ecosystem services for urban planning. Ecological Economics, 86(C), pp. 235-245, 2013. https://doi.org/10.1016/j.ecolecon.2012.08.019.

[10] Norton, B.A., Coutts, A.M., Livesley, S.J., Harris, R.J., Hunter, A.M. \& Williams, N.S.G., Planning for cooler cities: A framework to prioritise green infrastructure to mitigate high temperatures in urban landscapes. Landscape and Urban Planning, 134, pp. 127-138, 2015. https://doi.org/10.1016/j.landurbplan.2014.10.018.

[11] Miner, M.J., Taylor, R.A., Jones, C. \& Phelan, P.E., Efficiency, economics, and the Urban Heat Island. Environment and Urbanization, 29(1), pp. 183-194, 2017. https://doi.org/10.1177/0956247816655676.

[12] Hertel, W.F., A multi-city analysis of the natural and human drivers of Urban Heat Island. University of Minnesota, Aug. 2014.

https://conservancy.umn.edu/bitstream/handle/11299/166776/Hertel_umn_0130M_1 5243.pdf? sequence $=1 \&$ is Allowed $=\mathrm{y}$. 
[13] Sustainability DC, District of Columbia, Sept. 2011, p. 129, https://sustainable.dc.gov/ sites/default/files/dc/sites/sustainable/page_content/attachments/SDC $\% 20$ Final\% 20Plan.pdf.

[14] Rehan, R.M., Cool city as a sustainable example of heat island management case study of the coolest city in the world. HBRC Journal, 12(2), pp. 191-204, 2016. https://doi.org/10.1016/j.hbrcj.2014.10.002.

[15] Jennings, V., Floyd, M.F., Shanahan, D., Coutts, C. \& Sinykin, A., Emerging issues in urban ecology: implications for research, social justice, human health, and well-being. Population and Environment; New York, 39(1), pp. 69-86, 2017. http://dx.doi.org/10.1007/s11111-017-0276-0.

[16] Elmqvist, T. et al., Benefits of restoring ecosystem services in urban areas. Current Opinion in Environmental Sustainability, 14, pp. 101-108, 2015. https://doi.org/10.1016/j.cosust.2015.05.001.

[17] Escobedo, F.J. et al., Urban forests and pollution mitigation: Analyzing ecosystem services and disservices. Environmental Pollution, 159(8), pp. 2078-87, 2011. https://doi.org/10.1016/j.envpol.2011.01.010.

[18] The Demographic Statistical Atlas of the United States, Statistical atlas. https://statisticalatlas.com/metro-area/North-Carolina/Charlotte/Overview. Accessed on: 8 May 2020.

[19] Melillo, J.M., Richmond, T.C. \& Yohe, G.W. eds., Climate Change Impacts in the United States: The Third National Climate Assessment, U.S. Global Change Research Program, p. 841, 2014. https://doi.org/10.7930/J0Z31WJ2.

[20] Code of Ordinances, Code of ordinances city of Charlotte, North Carolina. Municode Library. https://library.municode.com/nc/charlotte/codes/code_of_ordinances?nodeId $=$ COORCHNOCA. Accessed on: 26 Feb. 2020.

[21] TreesCharlotte, Tree Canopy Conservation, Charlotte NC Nonprofit. https://treescharlotte.org/. Accessed on: 15 Apr. 2020.

[22] Chatham Park. Stewardship of Trees in Chatham Park. www.chathampark.com/ stewardship-of-trees-in-chatham-park/. Accessed on: 1 May 2019.

[23] Weston, P., Trees could lower London temperatures as UK summers get hotter. London Evening Standard. 26 March 2019. www.standard.co.uk/futurelondon/ cleanair/trees-could-lower-london-temperatures-as-uk-summers-get-hottera4101571.html.

[24] Li, W., Cao, Q., Lang, K. \& Wu, J., Linking potential heat source and sink to Urban Heat Island: Heterogeneous effects of landscape pattern on land surface temperature. Science of The Total Environment, 586, pp. 457-465, 2017. https://doi.org/10.1016/j.scitotenv.2017.01.191.

[25] DOEE, Department of Energy \& Environment. https://doee.dc.gov. Accessed on: 29 Feb. 2020. 